\title{
The Discourse of Guohua in Wartime Shanghai
}

\author{
Pedith Pui Chan \\ School of Oriental and African Studies, University of London, London, UK \\ pc65@soas.ac.uk
}

\begin{abstract}
This article looks at artists' engagement with artistic activities carried out in wartime Shanghai, with a particular focus on guohua (lit., 'national painting'). Drawing on primary sources such as archival materials, diaries, paintings, magazines and newspapers, it explores the layered meanings attached to and social functions of guohua and the institutional structure of the Shanghai art world from the gudao (solitary island) period to the advent of full occupation from December 1941 onwards. As a symbol of Chinese elite culture, guohua continued to dominate the Shanghai art world with support from Wang Jingwei's regime and the occupying Japanese, and was deemed the root of East Asian art and one of the crucial pillars of the East Asian renaissance in the discourse of the new order of East Asian art. Through closely examining the discourse of guohua in occupied Shanghai, this article advances our understanding of the production and consumption of art in wartime Shanghai by going beyond the paradigmatic binary of 'collaboration' and 'resistance'.
\end{abstract}

\section{Keywords}

art-guohua - Second Sino-Japanese War - Shanghai - occupation

\section{Introduction}

China's Nationalist government relocated its capital from Nanjing to the city of Chongqing in the southwest of the country as a result of the Second SinoJapanese War (1937-1945). Artists and resources from major cities such as Shanghai and Beijing migrated westward-either to Chongqing or elsewhere in the southwest, or to communist base areas in the northwest-resulting in an institutional reconfiguration of the Chinese art world. Accordingly, schol- 
arly research on the production of art in wartime China has hitherto focused on southwest and northwest China, with far less attention being paid to art in the occupied areas of east China.

This paper, however, looks at the devastating impact of the war on the production of art in occupied Shanghai, with a focus on the art form known as guohua (lit., 'national painting') and related artistic activities. It explores the layered meanings attached to and social functions of guohua during the occupation, as well as the extent to which the war affected artists' artistic choices and activities. The story of the Japanese occupation in Shanghai was, in many respects, quite different from that in other parts of China. In August 1937, a violent clash between the Nationalist Chinese and Japanese armies marked the beginning of the Battle of Shanghai. This battle lasted through until 12 November 1937, when the Chinese-controlled sections of Shanghai fell to Japan, marking the start of what has been known as the gudao ('solitary island') period (1937-1941); during this time, the International Settlement and French Concession in Shanghai were not occupied by the Japanese but the rest of the city was occupied. This would remain the case until December 1941, when, following the Japanese attack on Pearl Harbor, Shanghai's International Settlement was also occupied by the Japanese.

The cultural lives of artists in occupied China have long been overlooked by art historians, and the topic remains problematic and opaque. This is largely due to a lack of relevant primary sources, but is also the result of the sanitisation and distortion of history in China. To be sure, art in wartime China has recently attracted much scholarly attention. Most of the resulting research examines the role of art in the 'War of Resistance' (kangzhan), with a geographical focus on Chongqing, Yan'an and Guilin, and an emphasis on art forms such as oil painting, woodcuts and cartoons. ${ }^{1}$ Furthermore, most of this scholarship has centred on artistic representations of the devastating effects of the war, even though a significant body of artworks that seem to bear no direct description of the war were produced during the occupation. Only a handful of studies have focused on art in occupied China, namely

1 Those include Chang-tai Hung, War and Popular Culture: Resistance in Modern China, 19371945 (Berkeley: University of California Press, 1994); Chang-tai Hung, 'Two images of socialism: woodcuts in Chinese Communist politics', Comparative Studies in Society and History 39, 1 (January 1997): 34-6o; Huang Yuanlin (ed.) Bainian manhua (A Hundred Years of Cartooning), vols 1, 2 (Beijing: Xiandai chubanshe, 200o); Chou Fangmei, 'Zhongguo xihuajia de "Dongfang zhuyi"?-Di'erci shijie dazhan shi Zhongguo shaoshu minzu de xingxiang' (The Chinese Frontier-Images of Minorities during wwII), Yishuxue yanjiu (NCU Journal of Art Studies) 1 (June 2006): 59-101; Carolyn FitzGerald, Fragmenting Modernisms: Chinese Wartime Literature, Art and Film, 1937-1949 (Leiden: Brill, 2013). 
those by Nicole Huang and Jeremy E. Taylor. ${ }^{2}$ Building on the foundation of such scholarship, this paper examines the discourse of guohua in occupied Shanghai by going beyond the paradigmatic binary of 'collaboration' and 'resistance'.

'Collaboration' is an unavoidable topic when conducting research on the cultural lives of artists during the Japanese occupation. When it comes to collaboration in the cultural sector, Poshek Fu proposes a tripartite scheme of intellectual choices, namely passivity, resistance and collaboration, to explain the complexities of moral judgements during the occupation. ${ }^{3}$ Timothy Brook considers the complex issue of collaboration by looking at motives, actions and results. ${ }^{4}$ In the realm of art, however, what counts as 'collaboration'? Does it include attending exhibitions and joining activities organised by the occupiers? Does it include exhibiting one's paintings? Does receiving benefits from an occupier count as an act of 'collaboration'?

Scholarship on the French art world under Vichy offers useful insights and perspectives when considering the situation in occupied Shanghai. ${ }^{5}$ Laurence Bertrand Dorléac and Michèle Cone, for example, provide a detailed analysis of why artists supported Nazi and/or Pétainist projects, and how such artists responded to the German occupation. Bertrand Dorléac has reconstructed a complex picture of the Paris art world and provided careful accounts of the ambiguities embedded in artists' choices and attitudes. She contends that 'in reality, artists were far from sharing a single definition of engagement' with the collaborators or the resistance. ${ }^{6}$ Though Cone has discussed collaboration, she does not deal with the question of what it meant to be an artistic collaborator. ${ }^{7}$ The work of these two scholars shows that in the realm of art, artists' choices

2 Nicole Huang, Women, War, and Domesticity: Shanghai Literature and Popular Culture of the 1940 (Boston: Brill, 2005); Jeremy E. Taylor, 'Cartoons and collaboration in wartime China: the mobilization of Chinese cartoonists under Japanese occupation', Modern China 41, 4 (July 2015): 406-435.

3 Poshek Fu, Passivity, Resistance, and Collaboration: Intellectual Choices in Occupied Shanghai, 1937-1945 (Stanford, CA: Stanford University Press, 1993).

4 Timothy Brook, Collaboration:Japanese Agents and Local Elites in Wartime China (Cambridge, MA: Harvard University Press, 2005).

5 Michèle Cone, Artists under Vichy: A Case of Prejudice and Persecution (Princeton, NJ: Princeton University Press, 1992); Laurence Bertrand Dorléac, Art of the Defeat: France 1940-1944. Translated by Jane Marie Todd (Los Angeles: Getty Research Institute, 2008); Frederic Spotts, The Shameful Peace: How French Artists and Intellectuals Survived the Nazi Occupation (New Haven, CT: Yale University Press, 2008); Alan Riding, And the Show Went On: Cultural Life in Nazi-occupied Paris (New York: Alfred A. Knopf, 2010).

6 Bertrand Dorléac, Art of the Defeat, 68.

7 Cone, Artists under Vichy. 
and engagement with the occupiers was far more complex than the 'collaboration/resistance' binary would normally allow.

This paper looks at artists' engagement with artistic activities carried out in wartime Shanghai, with a particular focus on guohua. Thanks to its close association with Chinese literati culture, guohua provides us with the perfect case study through which to consider the elite cultural history of occupied China. Moral judgements have dominated the discourse on literati painting, and throughout Chinese history there are many examples of artists responding to dynastic changes involving 'alien' conquerors, such as the rise of the Mongols and Manchus. For instance, artists in the Yuan Dynasty turned to landscape painting to escape the turmoil caused by the Mongol invasion and to express their emotions by withdrawing into the natural world. Despite the fact that guohua experienced a cultural crisis generated by calls for an artistic revolution in the early twentieth century, its status was asserted and extolled by the Nationalist government in the 1930 secause of its association with 'traditional' culture. ${ }^{8}$ By situating the production and reception of guohua in the complex socio-cultural context of wartime Shanghai, this paper draws on primary sources such as archival materials, diaries, paintings, magazines and newspapers, examining the institutional structure of the Shanghai art world and artistic activities from the gudao period to the advent of full occupation from December 1941 onwards.

\section{And the Shows Went On ${ }^{9}$}

Examining the cultural history of Nazi-occupied France, Laurence Bertrand Dorléac, Michèle Cone, Alan Riding and Frederic Spotts have all demonstrated that cultural programmes resumed surprisingly soon after the German occupation began, and following a few months of decline. ${ }^{10}$ Galleries and museums reopened and the art market flourished as capital flowed in from the occupiers. A similarly unexpected bloom occurred in the art world in occupied Shanghai. As the cultural centre of China in the pre-war period, Shanghai had witnessed the rapid development of a robust art scene, drawing a considerable number of

8 Pedith Pui Chan, The Making of a Modern Art World:Institutionalisation and Legitimisation of Guohua in Republican Shanghai (Leiden: Brill, 2017).

9 The title is adopted from Alan Riding's book title And the Show Went On, aiming to show a similar unexpected boom in the art world in occupied Shanghai, the Paris of the East.

10 Cone, Artists under Vichy; Bertrand Dorléac, Art of the Defeat; Spotts, The Shameful Peace; Riding, And the Show Went On. 
artists and resources to the city. An unprecedented number of art schools and art societies were established in Shanghai, gathering like-minded artists and promoting various aesthetic approaches through exhibitions, periodicals and catalogues.

In March 1942, a retrospective article published in the newspaper Shenbao, entitled 'Unusual robust development [of art] in the past years', detailed developments in the cultural industry (fengya shiye 風雅事業) in Shanghai since the Battle of Shanghai in $1937 .{ }^{11}$ The author reported that, following the outbreak of war, the picture mounting business in Shanghai had in fact prospered to the extent that the most lucrative shop made 40,000-50,000 yuan per year. ${ }^{12}$ Evidently, people were keen to buy paintings and works of calligraphy. There were about 100 mounting shops in Shanghai, twenty of which operated on a large scale, employing more than 1,00o workers each. Liu Dingzhi's 劉定之 (18881964) shop was the most lucrative, specialising in mounting ancient paintings. ${ }^{13}$ The author also pointed out that in the pre-war period most of the buyers of paintings and calligraphy by contemporary artists had been antique dealers or well-educated private individuals. However, after August 1937, merchants who had made their fortune from the war-induced economic boom wanted to elevate their social status by socialising with artists and decorating their living rooms with paintings and calligraphy by famous artists. Exhibition galleries held exhibitions all year round. These attracted thousands of visitors, becoming a lucrative business. However, the article's author concluded that, with the outbreak of the Pacific War in December 1941, the art business went into a severe decline. $^{14}$

After the full occupation began at the end of 1941, all resources available to the Shanghai art world, from exhibition spaces to publication platforms, came under the control of the Japanese. As such, the information published in the media and exhibitions held in public spaces in this period reflect, to a large extent, the cultural policies imposed on the Shanghai art world by the occupiers. To restore 'normality' and reinvigorate the burgeoning Shanghai art world, art exhibitions continued to be held and art reviews and articles con-

\footnotetext{
11 'Nianlai jixing fada' (Unusually robust development [of art] in the past years), Shenbao, 9 March 1942: 3 .

12 The price of rice can be used as a reference for the cost of living in wartime Shanghai. The price of rice rose from 8.08 yuan per 5o kg in 1937 to 43.53 yuan in 1940. Yao Fei, 'A study of daily life in Shanghai during the isolated island period', Chinese Studies in History 47, 3 (2014): 41.

13 Liu Dingzhi was a renowned mounter in Shanghai.

14 'Nianlai jixing fada'.
} 
tinued to be published in magazines in this period. However, all of this came under the strict control of the 'collaborationist' regime led by Wang Jingwei.

Six review articles on the Shanghai art scene were published in the regimecontrolled magazine Taipingyang zhoubao (Pacific Ocean Weekly) between 1942 and $1944 .{ }^{15}$ These articles offer a glimpse of the Shanghai art world under full occupation, ${ }^{16}$ covering various art forms such as guohua, yanghua (oil painting) and muke (woodcuts), but focusing mainly on guohua and yanghua. They reveal that guohua works remained prominent in the Shanghai art world under full occupation, while yanghua declined in terms of both quality and quantity. Framed by the concept of 'Asia as One' (as advocated by Japan), these articles promoted art exhibitions and artistic exchanges between the Shanghai and Japanese art worlds. ${ }^{17}$

In a 1942 article entitled 'An annual review of the Shanghai art world', the author Zhu Weiqi (dates unknown) examined the Shanghai art world with reference to art exhibitions, art criticism, art organisations and popular art. Zhu argued that 'East Asian' culture should be created and built on the basis of both traditional and modern Chinese and Japanese culture. In the realm of art, exhibitions shouldered the responsibility for constructing this new 'Pan-Asian' culture. ${ }^{18}$ Zhu stated that a significant number of art exhibitions had been held in the past year, but that their quality had been disappointing. Most of the guo-

15 See Zhang Jie, 'Yishu zabi' (Miscellaneous writing on art), Taipingyang zhoubao (Pacific Ocean Weekly) 1, 20 (1942): 226-227; Ji Zhusheng, 'Guohua ji Shanghai de guohua jia' (National painting and national-style painters in Shanghai), Taipingyang zhoubao 1, 21 (1942): 248-249; Guangyi, 'Zuijin de Shanghai huatan' (The recent Shanghai art world), Taipingyang zhoubao 1, 40 (1942): 706; Zhu Weiqi, 'Yi nian lai Shanghai meishu jie qingsuan' (An annual review of the Shanghai art world), Taipingyang zhoubao 1, 49 (1942): 929931; Zhu Weiqi, 'Chuchun Shanghai huatan' (The Shanghai art world in early spring), Taipingyang zhoubao 1, 63 (1943): 1278; Zhu Weiqi, 'San'er nian Shanghai meishu jie zongjian' (A review of the Shanghai art world in 1943), Taipingyang zhoubao 1, 93 (1944): 20962097 .

16 Fang Changhao was the editorial director and chief editor. The magazine was registered with the government. Xu Wancheng, Quanguo wenhua jiguan diaocha (An investigation into national cultural institutions) (Shanghai: Longwen shudian, 1943), 5 .

17 Brij Tankha, Okakura Tenshin and Pan-Asianism: Shadows of the Past (Leiden: Brill, 2008).

18 For a discussion of 'Pan-Asianism' see Prasenjit Duara, 'The discourse of civilization and Pan-Asianism', Journal of World History 12, 1 (Spring, 2001): 99-130; Sven Saaler and Victor Koschmann (eds), Pan-Asianism in Modern Japanese History: Colonialism, Regionalism and Borders (Abingdon: Routledge, 2007); Tankha, Okakura Tenshin and Pan-Asianism; Sven Saaler and Christopher W.A. Szpilman (eds), Pan-Asianism: A Documentary History (Lanham, MD: Rowman \& Littlefield, 2011); Sven Saaler, 'The Kokuryūkai (Black Dragon Society) and the rise of nationalism, Pan-Asianism, and militarism in Japan, 1901-1925', International Journal of Asian Studies 11, 2 (2014): 125-16o. 
hua exhibitions had been designed for the purpose of selling art works, while the few yanghua exhibitions that had been held were of poor quality. Thus, the Sino-Japanese Cultural Association (Zhong-Ri wenhua xiehui) 中日文化協 會 (sJCA) — an organisation to be examined at length below — gathered leading yanghua artists, such as Chen Baoyi 陳抱一 (1893-1945), Wang Yachen 汪亞塵 (1894-1983) and Yan Wenliang 顏文樑 (1893-1988), in the hope of establishing a Shanghai yanghua association. However, Wang and Yan showed no enthusiasm for this proposal, making it impossible to unite yanghua artists in Shanghai. ${ }^{19}$ Chen, Wang and Yan were crucial art educators and leading artists in promoting Western art in pre-war Shanghai. Both Chen Baoyi and Wang Yachen graduated from the Tokyo School of Fine Arts, so it is understandable that they were invited by the Wang Jingwei regime to lead and gather oil painters in Shanghai.

Zhu Weiqi penned two more reviews in 1943 and 1944, each with an emphasis on art exhibitions and artistic exchanges. The featured exhibitions by Chinese artists included solo shows by the oil painter Zhou Bichu 周碧初 (1903-1995), the sculptor Zhang Chongren 張充仁 (1907-1998) and the guohua artists Wang Yachen and Pu Xuezhai 溥雪齋 (1893-1966); a group show by young Chinese oil painters; a joint exhibition on guohua by Wu Hufan 吳湖帆 (1894-1968) and his students; a joint exhibition by four women artists; ${ }^{20}$ and a joint exhibition of guohua by Zheng Wuchang 鄭午昌 (1894-1952) and his students. The Japanese exhibitions mentioned by Zhu included a solo show by the Japanese oil painter Kondo Goro, a group exhibition of Chinese and Japanese Westernstyle paintings; and joint exhibitions of modern Japanese painting, sculpture and ukiyo-e prints (a genre of Japanese art often referred to as 'pictures of the floating world'). ${ }^{21}$ Intriguingly, these reviews reveal a new order in the Shanghai art world, suggesting that not only local but also Japanese artists were competing for resources in the city.

Guohua continued to play a dominant role in exhibition culture. Some guohua artists were specifically mentioned in the articles, including Wu Hufan, Zheng Wuchang, Li Qiujun 李秋君 (1899-1973) and Chen Xiaocui 陳小翠 (1907-1968). Most of these artists were core members of the prominent guohua societies, namely the Painting Association of China (Zhongguo huahui) and the Chinese Women's Painting and Calligraphy Association (Zhongguo nüzi

19 Guangyi, 'Zuijin de Shanghai huatan', 7o6; Zhu, 'Yi nian lai Shanghai meishu jie qingsuan', 929-931.

20 These being Feng Wenfeng (1906-1971), Chen Xiaocui (1907-1968), Gu Fei (1907-2008) and Xie Yuemei (dates unknown).

21 Zhu, 'Chuchun Shanghai huatan', 1278; Zhu, 'San'er nian Shanghai meishu jie zongjian', 2096-2097. 
shuhuahui) (CWPCA). They were the most prestigious art associations in the pre-war Shanghai art world. ${ }^{22}$

Although these reviews may not offer an objective evaluation of the Shanghai art scene (owing to publication restrictions and censorship), they nonetheless provide a brief profile of the Shanghai art world, and foreground the crucial role played by exhibition culture in wartime Shanghai. A survey of the exhibitions held in wartime Shanghai was conducted based on information collected from newspapers and magazines. The data suggests that the number of art exhibitions increased significantly after the Battle of Shanghai, surpassing the number of exhibitions that were held in the pre-war period. Seventy-four exhibitions were held in Shanghai between January and July 1937, but only six were held between August and December, and twenty-two were held in 1938 . In the gudao period, Shanghai's International Settlement and French Concession continued to enjoy relative economic success and freedom, fuelling the development of the Shanghai art world, as reported in the reviews discussed above. During the gudao period, over 320 exhibitions were held in Shanghai (109 per year), whereas over 504 were held during the period of full occupation (1942-1945).

Furthermore, the survey confirms the observation made in review articles that guohua - both ancient and contemporary-continued to enjoy prominence within Shanghai's exhibition culture. In the gudao period, over 6o per cent of the exhibitions held focused on guohua, with a slight decline during the full occupation, during which time there was a significant increase in exhibitions of Japanese modern paintings and oil paintings. However, according to one critic, 'regarding the exhibitions held at the Dah Sun Art Gallery ... the number of guohua exhibitions outweighed yanghua many times' 過去大新畫廳所 舉行過的畫展 ... 國畫的展覽當然是比洋畫要多出數倍哩 ${ }^{23}$ and 'throughout the year, the number of guohua exhibitions is magnificent in Shanghai' 在上 海, 一年到頭, 國畫展覽會的數目相當可觀. ${ }^{24}$ As 'artworks were regarded as [a] commodity in Shanghai' 藝術品被目為商品的今日的上海, ${ }^{25}$ it is not surprising that most of the guohua exhibitions in Shanghai during this period, whether showing ancient or contemporary Chinese paintings, focused on sales. In fact, in wartime Shanghai, artists' everyday lives were adversely affected by continuous inflation. Because of the rising prices of art equipment and oil

\footnotetext{
22 Chan, The Making of a Modern Art World, 32-64.

23 Ji, 'Guohua ji Shanghai de guohua jia', 248-249.

24 Wang Cheng, 'Xin qiu san huazhan' (Three exhibitions of paintings in early autumn), Taipingyang zhoubao (Pacific Ocean Weekly) 1, 81 (1943): 1764.

25 Ji, 'Guohua ji Shanghai de guohua jia', 248-249.
} 
paints, oil painters such as the renowned oil painter Wang Yachen shifted to guohua to earn a living only by selling their paintings. ${ }^{26}$ This change is reflected in the survey.

Furthermore, the survey shows that exhibitions were held in certain popular venues within the foreign concessions, such as the Ningbo Native Place Association (Ningbo tongxianghui) and the Dah Sun Department Store (Daxin gongsi). The Ningbo Native Place Association (NNPA) was located on Sitzang Road (Xizang Lu), and the Dah Sun Department Store on Nanking Road (Nanjing $\mathrm{Lu}$ ). Both venues held over 180 exhibitions between 1937 and 1945. The NNPA had been a popular exhibition venue before the war, and remained so in wartime. The Dah Sun Department Store opened in 1936 and reserved an exhibition space, named the Dah Sun Gallery, for showcasing Chinese products, although eventually most of the exhibitions held in this space related to art. This gallery was regarded as the best-equipped exhibition venue in Shanghai, its fame even surpassing that of the NNPA. Dah Sun Art Gallery was considered well managed, 'tidy and comfortable' 整齊而舒暢, and in a good location. However, some artists and exhibition organisers complained about the high commission fees and the unfair and restrictive terms offered by this gallery. This may in part explain why the gallery closed in July $1943 .{ }^{27}$ In November 1944, a new gallery space opened on the second floor of the Dah Sun Department Store.

New exhibition venues were also established, particularly after the start of the full occupation. These included the Shanghai Tairiku Gallery, which opened in 1942 (and which mainly exhibited oil paintings), and the Shanghai Art Gallery on Zhejiang Road, which opened in 1943. As these venues were operated by Japanese organisations, they were designed specifically for Japanese art and propaganda exhibitions. For instance, the Shanghai Tairiku Gallery was operated by the Shanghai-based Japanese-language newspaper Tairiku Shinpō and organised exhibitions of Japanese art, particularly modern Japanese paintings. ${ }^{28}$

In response to the growing demand for exhibition space (particularly following the closure of the Dah Sun Gallery), the Chinese Painting Garden (Zhong-

\footnotetext{
26 Wang Zhen, Wang Yachen Rong Junli nianpu hebian (Chronology of the Life of Wang Yachen and Rong Junli) (Beijing: Minzhu yu jianshe chubanshe, 1996), 275-277; Shenbao nianjian (minguo sanshisan nian du) (Shenbao Yearbook, 1944) (Shanghai: Shenbao nianjian she, 1944), 1020-1021.

27 Yin'an, 'Lidai shuhua zhan canguan ji' (Notes on a visit to an exhibition of paintings and calligraphy), Rensheng (Life) 1, 3 (1943): 16.

28 'Jian xun' (Brief news), Shenbao, 2 July 1944: 3.
} 
guo huayuan), a share company, was established in August 1943 and became one the most popular venues for art exhibitions. ${ }^{29}$ Located on Chengtu Road (Chengdu Lu), the gallery served as both an exhibition venue and an exhibition organiser, showcasing and selling artworks on behalf of clients. The founders came from the art and commercial sectors, and included individuals such as Li Zuhan 李祖韓 (1891-?), Chen Xiaodie 陳小蝶 (1897-1989), Qin Ziqi 秦子奇 (dates unknown), Chen Zitang 陳滋堂 (dates unknown), Xu Bangda 徐邦達 (1911-2012) and Wang Jiqian 王季遷 (1907-2003). ${ }^{30}$ Xu Bangda and Wang Jiqian were students of the leading artist Wu Hufan, who had been friends with Wang Jingwei for a long time through sharing an interest in ci poetry. Xu and Wang are remembered as reputable and influential connoisseurs with important roles in collecting and authenticating Chinese ancient paintings and calligraphy. Qin Ziqi and Chen Zitang held high positions in the insurance and banking industries. Li Zuhan came from a prominent Ningbo family, and Chen Xiaodie was the son of an industrialist. Both Li and Chen were core members of the Painting Association of China and had close connections with prominent guohua artists. For instance, Li's sister Li Qiujun and Chen's sister Chen Xiaocui were both founders of the CWPCA.

The background of the founders of the Chinese Painting Garden therefore reflected the commercial nature and artistic preferences of the gallery, which operated with the blessing of the Wang Jingwei regime. In his memoirs, Chen Xiaodie described the Chinese Painting Garden as a society-like organisation that provided not only an exhibition venue but also an artists' studio, the Eastern Studio (Dong xuan), that was equipped with painting materials and equipment for members. Unsurprisingly, therefore, most of the exhibitions held at this gallery showcased guohua, both ancient and contemporary. For instance, the gallery's inaugural exhibition gathered over 300 ancient paintings and calligraphy from renowned collectors such as Peng Laichen 龐萊臣 (1864-1949), the most prominent private collector in the Jiangnan region. The admission fee for this exhibition was high (at 20 yuan per visitor), ${ }^{31}$ but the exhibition was well received because of the quality of the works on display. Thanks to the founders' social network, the gallery was able to distinguish itself from other galleries by demonstrating its ability to connect to the prestigious collector

29 Chen Dingshan, 'Zhongguo huayuan zheng hua ji' (Chinese Painting Garden's call for paintings), Shenbao, 29 August 1943: 3 .

30 'Zhongguo huayuan kaimu yugao' (Advance notice about the opening of the Chinese Painting Garden), Shenbao, 20 August 1943: 1.

31 Chen Dingshan, Chunshen jiuwen (Old Stories of Shanghai) (Taipei: Duli zuojia, 2016), 120; Chen, 'Zhongguo huayuan zheng hua ji', 3. 
community and guohua artists, and to secure good revenue even during the period of the full occupation. ${ }^{32}$

As demonstrated in the above discussion, some artists' names were appearing frequently in reviews within the exhibition culture in wartime Shanghai, showing that a new order had been formed. By 1937, veteran artists such as Zeng Xi 曾熙 (1861-1930) and Li Ruiqing 李瑞清 (1867-1920) had passed away, and the leading artist Wang Yiting left Shanghai in November 1937 and passed away in Hong Kong in 1938. Huang Binhong 黃賓虹 (1865-1955) left Shanghai for Beijing in 1937 and was not able to return to Shanghai owing to the war. ${ }^{33}$ All these changes established a new hierarchical order in the Shanghai art world. The names of Wu Hufan, Zheng Wuchang, Li Qiujun and Chen Xiaocui were associated with exhibitions and mentioned in newspapers, and their students became active in the art world.

\section{3}

\section{Societal Exhibitions on Guohua}

The artists frequently cited in the press were in fact core members of two prominent art societies. Art societies had played a pivotal role in promoting and institutionalising the arts in the pre-war period. However, while art societies before the war participated extensively in organising art exhibitions, most of the exhibitions held during the occupation were organised by paper-and-fan shops (jianshan dian), exhibition organisers and Japanese organisations. The two most prominent guohua societies, the CWPCA and the Painting Association of China, were among the few exceptional cases. ${ }^{34}$ The 1947 Yearbook of Chinese Art (Zhongguo meishu nianjian) provides information on the development of art in modern China, such as biographies of artists, information on art societies, images of artworks and essays. Through a close reading of the accounts of art societies, one can see how the stories of war and occupation were told and untold.

32 Woxin, 'Zhongguo huayuan xingjiang jieshu' (Chinese Painting Garden will close soon), Daguanyuan zhoubao (Panorama Garden Weekly) 4 (March 1946): 4.

33 For the hierarchical structure of the pre-war Shanghai art world, see Chan, The Making of a Modern Art World.

34 Chan, The Making of a Modern Art World; Julia F. Andrews and Kuiyi Shen, 'Traditionalism as a modern stance: the Chinese Women's Calligraphy and Painting Society of $1930 \mathrm{os}$ Shanghai', Modern Chinese Literature and Culture 11, 1 (Spring 1999): 1-29. 
As the most prominent guohua societies in the pre-war period, the membership of CWPCA and the Painting Association of China included almost all the reputable female and male guohua artists in Shanghai. The social and symbolic capital the societies accumulated in the pre-war period was able to be exchanged for resources, such as exhibitions in the wartime period. According to the CWPCA, 'in the pre-war period, the association had over 150 members from all over the nation and organised exhibitions annually. The exhibitions ceased with the fall of Shanghai and resumed after victory' 抗戰以前, 擁有 各地會員一百五十餘人, 規定每年舉行畫展一次, 除渥上淪陷時一度停頓 外, 勝利後又恢復舉行矣. ${ }^{35}$ The yearbook account of the Painting Association of China states that "[the association] organised an exhibition on guohua and calligraphy to aid soldiers' 舉行過一次慰勞抗戰將士書畫展, and that

during the War of Resistance, some of the members retreated to the 'great hinterland' (da houfang) while the remainder stayed in Shanghai. Due to the unfavourable circumstances, the association ceased its societal activities and never collaborated with the puppet regime and occupiers.

抗戰期間, 一部分會員遄赴大後方工作, 一部分會員留居淈上, 因環 境關係, 自行停止會務, 絕未與敵偽合作. ${ }^{36}$

Such accounts provide a brief and officially sanctioned narrative of how art societies responded to the war. However, such accounts also reveal that some information remains untold.

To be sure, these associations jointly organised an exhibition to aid the war effort against the Japanese in November 1937. This brought together 722 works, and raised around 7,257 yuan for the war effort. ${ }^{37}$ However, these organisations did not cease their activities immediately following the Japanese invasion, as the post-war accounts suggest. On the contrary, scattered information published in newspapers reveals the fact that both associations organised exhibitions during the occupation. Shortly after the jointly organised fundraising exhibition, the CWPCA launched its annual societal exhibition in November

35 Wang Yichang (ed.) Zhongguo meishu nianjian, 1947 (1947 Yearbook of Chinese Art), History 9 (Shanghai: Shanghai shi wenhua yundong weiyuanhui, 1948).

36 Wang, Zhongguo meishu nianjian, 6.

37 'Weilao jiangshi shuhua zhan zuo bimu' (Calligraphy and painting exhibition for the consolation of soldiers closed yesterday), Shenbao, 6 November 1937: 6; 'Weilao huazhan jieshu' (Closing of the painting exhibition for the consolation of soldiers), Shenbao, 12 November 1937: 9 . 
1938 , with the aim of raising funds so that they could donate winter clothing to children. The exhibition gathered works from its members, including newly enrolled members. Interestingly, an introduction to the exhibition published in Shenbao highlighted Niu Xunyan 鈕恂言 (dates unknown), a little-known artist, stating that she was the niece of Niu Tisheng 鈕惕生 (1870-1965), who was the Associate Director of the Examination Yuan (Kaoshiyuan), and that she excelled in landscape painting. It also emphasised that Niu Xunyan's recent solo exhibition held in Beijing had attracted important politicians. ${ }^{38}$ On its second day, the CWPCA exhibition received 2,ooo visitors, including leading artists such as Wu Hufan, Li Zuhan and Wang Yachen, as reported in Shenbao. ${ }^{39}$

In November 1939, the CWPCA launched another annual exhibition at a popular exhibition venue- the NNPA. The advertisements for and reports about this exhibition, unlike the previous exhibitions, did not mention fundraising; instead, they emphasised the number of CWPCA members involved and their family backgrounds. The exhibition included the works of 200 members. One of its newly enrolled members was the daughter of Tan Yankai 譚延闘 (18801930), who had been a high-ranking politician in the Nationalist government prior to the war. ${ }^{40}$ From 1940, the CWPCA held its annual exhibitions in the popular new art gallery at the Dah Sun Department Store. At its 1940 exhibition, it showcased over 400 works, more than 9o per cent of which were sold in just five days. ${ }^{41}$ The 1941 annual exhibition exhibited between 400 and 600 works. ${ }^{42}$ (See Figure 1.) The CWPCA's annual exhibitions ended with the full occupation of Shanghai, but then resumed in 1943. In 1943 and 1944, they were held in the newly established Chinese Painting Garden. The 1944 exhibition included over 300 works by forty of the CWPCA's members, such as Li Qiujun and Chen Xiaocui. ${ }^{43}$

$38 \quad$ 'Nüzi shuhuahui wu jie zuopin zhanlan' (The Fifth Exhibition of works by the Chinese Women's Painting and Calligraphy Association), Shenbao, 26 November 1938: 12.

39 'Nüzi shuhua zhan di er tian shengkuang' (The success of the Exhibition of Calligraphy and Paintings by Female Artists on the second day), Shenbao, 28 November 1938: 11.

40 'Nüzi shuhuahui jin kaimu' (Exhibition of works by the Chinese Women's Painting and Calligraphy Association opens today), Shenbao, 11 November 1939: 12.

'He Tianjian shuhua xun' (Painting-and-calligraphy news of He Tianjian), Shenbao, 14 November 1940: 11.

42 'Nüzi shuhua zhan kaimu' (Exhibition of Calligraphy and Paintings by Female Artists opens), Shenbao, 8 November 1941: 8; 'Nüzi shuhuahui zuo kaimu' (Exhibition of works by the Chinese Women's Painting and Calligraphy Association opened yesterday), Shenbao, 9 November 1941: 10.

43 'Jieyue yundonghui juxing xuanchuan zhou' ([Organisers of] the Savings Campaign hold the promotion week), Shenbao, 8 November 1943: 2; 'Jian xun' (Brief news), Shenbao, 26 November 1944: 2. 


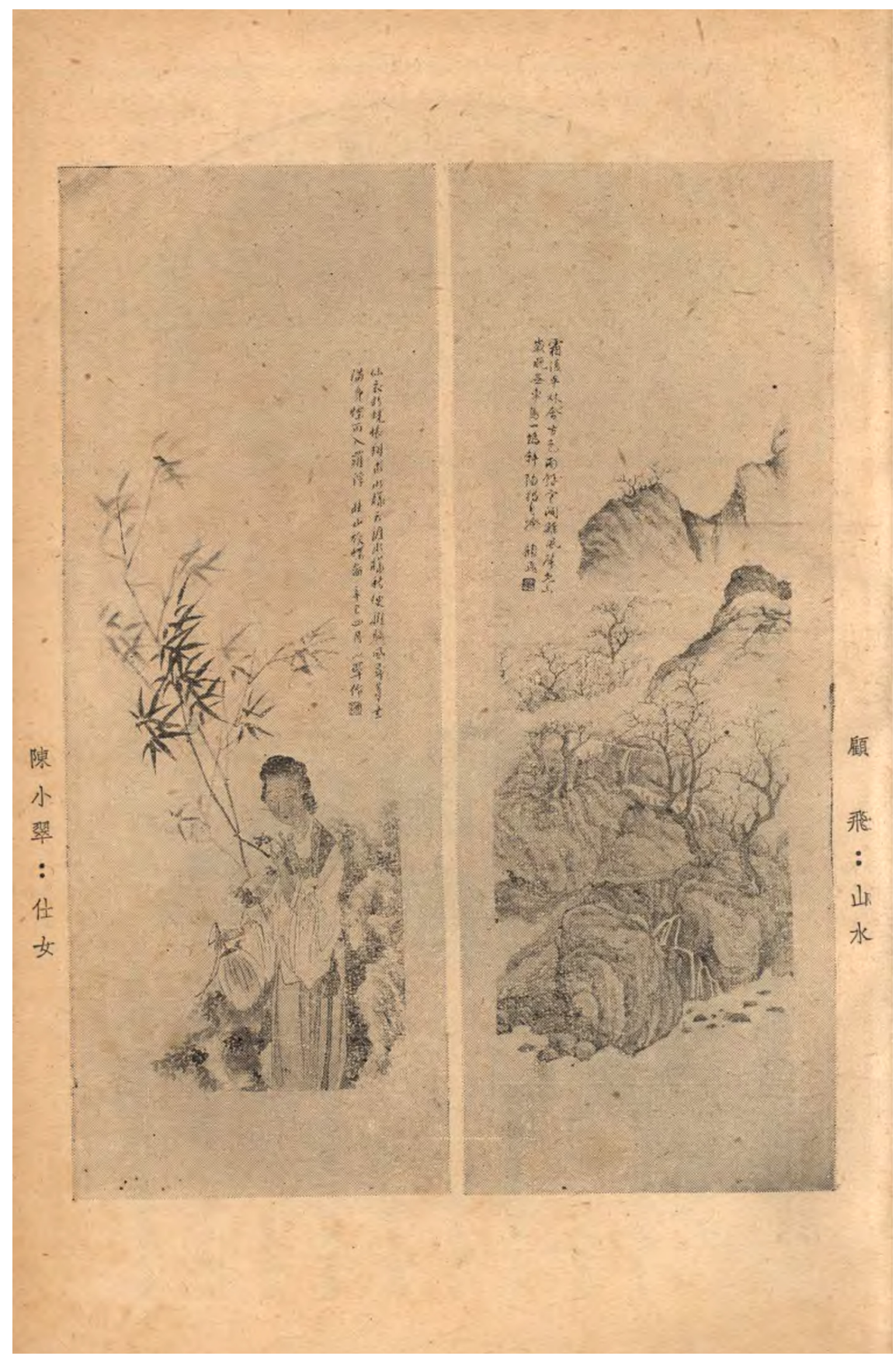

FIGURE 1 A figure painting by Chen Xiaocui (left) published in the magazine The Dah Loh Monthly in 1941 
Meanwhile, the Painting Association of China organised its seventh societal exhibition in December 1938 with the aim of raising funds to purchase winter clothing for refugees. The exhibition was held at the Dah Sun Gallery and included over 400 exhibits, including fourteen works by the prestigious member and veteran artist Wang Yiting 王一亭 (1867-1938), who had just passed away. ${ }^{44}$ In the following years, the Painting Association of China elected committee members and organised two more annual societal exhibitions in 1939 and 1940, respectively. ${ }^{45}$ Advertisements for these exhibitions no longer mentioned 'relief aid' but simply provided information on the exhibitions themselves. From late 1941 onwards, the departure of some of the society's members and the extension of the Japanese occupation to the foreign concessions resulted in the cessation of these societal exhibitions. Instead, the 'core members of the Association', including Sun Xueni 孫雪泥 (1889-1965) and Qian Shoutie 錢瘦鐵 (1897-1967), organised a group show in November 1941. ${ }^{46}$ This exhibition gathered over 100 works by artists such as Zheng Wuchang and Wang Yachen. ${ }^{47}$ In addition, although the annual societal exhibitions had been discontinued, the societal members who stayed in occupied Shanghai participated actively in other exhibitions. In 1943, Wu Hufan and Zheng Wuchang organised joint exhibitions with their own students; both were well received and widely covered in the press. Wu Hufan's group show was praised as 'shaking the Shanghai art world' 震撼了上海畫壇 because 'Wu holds an extraordinary position in the guohua field' 吳氏在國畫家的地位畢竟高人一等. ${ }^{48}$ Liu Haisu 劉海粟 (1896-1994), Sun Xueni, Wang Yachen and Qian Shoutie held solo exhibitions during the full occupation. (See Figure 2.) Liu Haisu's solo show was highly praised, with the artist described as 'the master of Asia's cultural renaissance' 東方文藝復興大師 in Pacific Ocean Weekly. ${ }^{49}$

44 'Ge shangtuan lingxiu jiyi Wang Yiting sishi' (Leaders of corporations discussed the posthumous name of Wang Yiting), Shenbao, 10 December 1938: 1.

45 The eighth committee of the Painting Association of China was elected. It included Wang Yachen, Zhang Yuguang, He Tianjian, Zheng Wuchang and Lu Danlin as managing directors. Lu Danlin, Sun Xueni, He Tianjian, Zheng Wuchang, Zhang Yueguang, Qian Soutie, Xie Gongzhan, Ma Gongyu, Zhang Daqian, Ding Nianxian, Wang Shizi and Chen Xiaodie were executive members. Wang Zhen, Wang Yachen Rong Junli nianpu hebian, 270.

46 'Xin yaji qiu xing huazhan' (New elegant gathering of the painting exhibition in autumn), Shenbao, 28 October 1941: 8.

47 'Xin yaji qiu xing huazhan', 8.

48 Zhu, 'Chuchun Shanghai huatan', 1278.

49 Wang Yuren, 'Liu Haisu yinxiang' (Impressions of Liu Haisu), Taipingyang zhoubao (Pacific Ocean Weekly) 1, 22 (1942): 275 . 


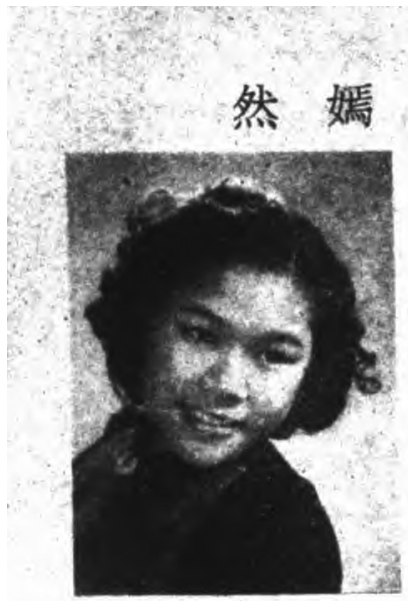

士女芳慕嚴

\begin{tabular}{|c|c|c|c|}
\hline 鞎 & 考 & 明 & 雄 \\
\hline 助 & 取 & -女 & -女 \\
\hline 學 & - & 中 & $士$ \\
\hline 企 & 九 & 高 & 乎 \\
\hline$z$ & 四 & 材 & + \\
\hline 第 & 三 & 生 & 六 \\
\hline - & 年 & , & , \\
\hline 人 & 秋 & 禺 & 上 \\
\hline 10 & 季 & 故 & 海 \\
\hline & 申 & 校 & 掊 \\
\hline
\end{tabular}

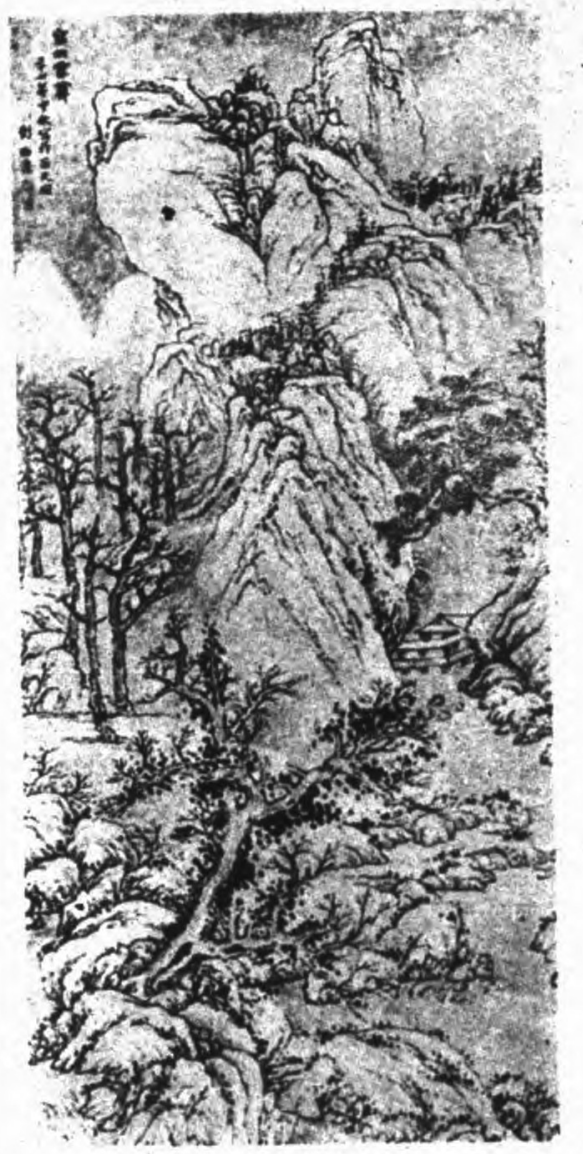

\section{震雪山寒}

・作粟海劉・

FIGURE 2 A landscape painting by Liu Haisu published in the magazine Ziluolan in 1944

The information collected from the newspapers and magazines suggests that the CWPCA and the Painting Association of China did organise annual exhibitions and their core members continued to engage actively with exhibition culture during the full occupation. The flourishing exhibition culture and the numbers of exhibits included in each exhibition were impressive, reflecting the fact that artists became unexpectedly productive during the war. How- 
ever, it is worth noting that the reports and reviews published in newspapers provided little information about the works of art, instead providing a list of names of prominent artists and cultural figures. For instance, CWPCA members' family backgrounds and their connections with the male elite were highlighted. Among the names listed, Wu Hufan and Liu Haisu were highly extolled. Wu was a renowned artist, collector and connoisseur in the Shanghai art world. Through his knowledge of art and his reputation in the art world, Wu Hufan built connections with the leaders of the Wang Jingwei regime, including Wang Jingwei, Chu Minyi (1884-1946), Chen Gongbo (1892-1946) and Zhou Fohai (1897-1948). Liu Haisu was a crucial figure in the Shanghai art world: he was the founder of the prestigious Shanghai Academy of Arts (Shanghai Meizhuan) and had organised several overseas exhibitions of contemporary Chinese painting on behalf of the Nationalist government. Therefore, it is undoubtedly these prominent artists who were targeted by the Wang Jingwei regime as the potential leaders of the Shanghai art world during the full occupation.

\section{The Sino-Japanese Cultural Association: Peace and Collaboration}

Initiated by Chu Minyi in autumn 1939, the Sino-Japanese Cultural Association (SJCA) was created to promote Wang Jingwei's Peace Movement after the inauguration of Wang's regime in $1940 .{ }^{50}$ This association, funded by Wang's regime, was officially responsible for handling cultural activities and propaganda. ${ }^{51} \mathrm{It}$ aimed to bridge the gap between the Chinese and Japanese cultural sectors and promote 'Asian civilisation', and was in charge of a wide variety of activities, such as academic research, exhibitions, talks, film screenings and cultural exchanges. ${ }^{52}$ Through regular cultural activities and plans for future cultural construction, such as museums, the idea of reviving and constructing Chinese culture as well as 'East Asian' (Dong Ya) culture was advocated by this group. Interestingly, the Chinese art form of 'painting-and-calligraphy' (shuhua) was included in a list of regular activities in the association's 1940 report. ${ }^{53}$ The SJCA also established its own art section in 1942; this section was tasked with 'pro-

50 Chu Minyi, Zhong-Ri wenhua xiehui kaimu dianli tekan (Special Issue on the Opening of the Sino-Japanese Cultural Association) (Np: Zhong-Ri wenhua xiehui, 1940).

$5^{1}$ The government offered 50,00o yuan to launch the association and 20,00o yuan monthly funds. Chu, Zhong-Ri wenhua xiehui kaimu dianli tekan, 10.

$5^{2}$ 'Zhong-Ri wenhua xiehui yuanqi' (The origins of the Sino-Japanese Cultural Association), Waijiaobu gongbao (Bulletin of the Ministry of Foreign Affairs) 7 (1940): 19-20. 
moting our national essence - painting-and-calligraphy, bronze-and-stele, and sculpture'發揚我國固有國粹之書畫金石雕刻. ${ }^{54}$ Although the official purpose of the SJCA thus was to propagate the ideology of Wang's regime and the occupying Japanese, it also sought to promote a sense of 'national essence', thereby diluting Japan's increasing dominance in the discourse of art.

The Shanghai branch of the SJCA was established in 1941, before the advent of the full occupation at the end of that year. Its committee members were from China and Japan. According to its 1941 report, the branch organised two art exhibitions between April and July: one of shuhua and bronze-and-stele, and another of yanghua. The exhibition on shuhua gathered more than 400 valuable artworks by ancient masters and contemporary artists. Some exhibits were put up for sale, with prices ranging from 6oo to 6o,ooo yuan. To attract artists and collectors, prizes were made available for collectors willing to lend items from their collections to the exhibition and artists willing to collaborate with the association. The SJCA's report claimed that the exhibition was well received. However, judging from media coverage, the exhibition did not attract reputable collectors and artists..$^{55}$ The Shanghai branch appears to have been unable to engage artists and collectors in Shanghai within the first year of its establishment. This is evident from the make-up of the committee of the Shanghai branch, which did not include renowned artists from the Shanghai art scene. On the second anniversary of the association's establishment, the only prominent members of the Shanghai art world to be listed were Huang Juesi 黃覺寺 (1901-1988) and Ye Minchu 葉敏初 (dates unknown). ${ }^{56}$

In 1941, to celebrate the first anniversary of the establishment of Wang Jingwei's RNG, a special exhibition was organised by the SJCA..$^{57}$ This exhibition showcased not only relevant historical documents but also works of art, particularly ancient paintings collected by high officials in the Wang regime. (See Figure 3.) More than 100 precious paintings and works of calligraphy were collected, including, as reported in an exhibition review, landscapes by Shen Zhou 沈周 (1427-1509), Xu Wei 徐渭 (1521-1593), Shitao 石濤 (1642-1707) and Wang

54 Zhong-Ri wenhua xiehui (ed.), Zhong-Ri wenhua xiehui er zhounian jinian tekan (Special Issue on the Second Anniversary of the Sino-Japanese Cultural Association) (Np: ZhongRi wenhua xiehui, 1942), 91.

Zhong-Ri wenhua xiehui (ed.), Zhong-Ri wenhua xiehui Shanghai fenhui gongzuo baogao (Report on the Work of the Shanghai Branch of the Sino-Japanese Cultural Association) (Np: Zhong-Ri wenhua xiehui, 1942).

56 Zhong-Ri wenhua xiehui (ed.), Zhong-Ri wenhua xiehui er zhounian jinian tekan.

57 Zhong-Ri wenhua xiehui (ed.), Zhong-Ri wenhua xiehui zhounian jinian tekan (Special Issue Commemorating the First Anniversary of the Sino-Japanese Cultural Association) (Np: Zhong-Ri wenhua xiehui, 1941). 


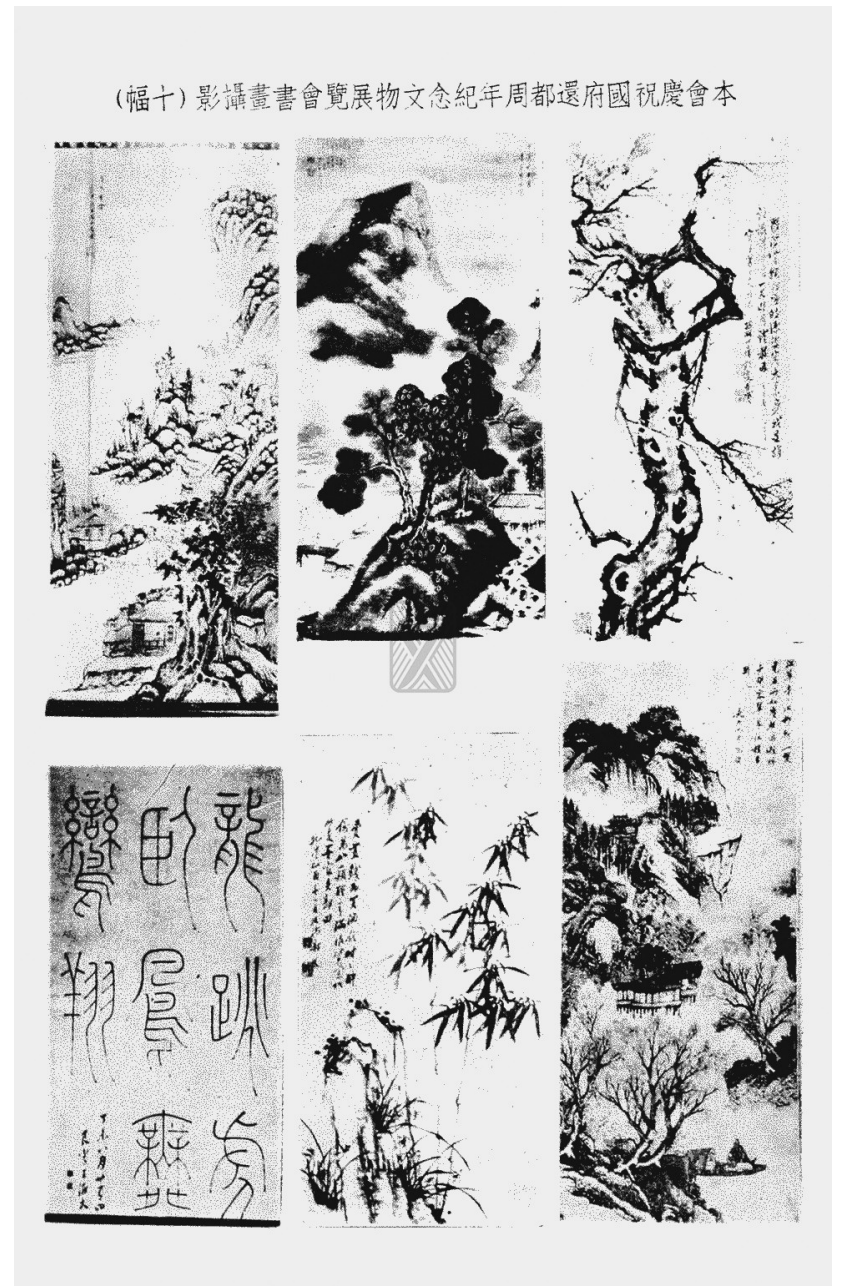

FIGURE 3 A view of the exhibits included in the exhibition celebrating the anniversary of the 'return to the capital', Zhong-Ri wenhua xiehui zhounian jinian tekan, in 1941

Hui 王啎 (1632-1717); an orchid painting and calligraphy by Wen Zhengming 文 徵明 (1470-1559); and calligraphy by the revolutionary leader Sun Yat-sen. The author claimed that 'we can see a lot of national treasures at the celebration of the "return to the capital" [huandu,$^{58}$ reflecting the profundity and diversity

$5^{8}$ The huandu refers to Wang Jingwei's return to Nanjing in March 1940, and the subsequent establishment of his wartime regime. 
of Chinese culture 我們在還都紀念能够看到這許多國寶, 深信中國文化的 淵藏, 還相當豐富. ${ }^{59}$ The exhibition intentionally showcased aspects of elite Chinese culture that was valued by high-ranking officials in Wang's regime.

With the start of the full occupation of Shanghai in December 1941, further pressure was exerted on Shanghai's art scene. Art schools, the press, exhibitions and art associations were censored and required to register with the government. The SJCA became the only lawful cultural organisation in occupied Shanghai. An examination of internal sJCA documents provides a deeper understanding of what the association did to accomplish its goals between May and November $1942 .{ }^{60}$ In the twelve exhibitions recorded in the documents, Zhongguo hua (lit., 'Chinese painting') was prominent in terms of coverage and quantity. The names of leading guohua artists were highlighted to promote the exhibitions and the association. For instance, a report of an exhibition of paintings and calligraphy by famous Chinese artists held in May 1942, published in the magazine Art in Shanghai Monthly, highlighted the names of Wu Hufan, Zheng Wuchang and Wang Yachen. ${ }^{61}$ Zheng Wuchang and Ma Gongyu 馬公 愚 (1894-1969) were also mentioned in the report, as they had been recommended by the association to join the Fourth Painting and Calligraphy Exhibition held by the Union of Reviving Asia Calligraphy held in Beijing. ${ }^{62}$ They received awards at the exhibition. After being shown in Beijing, the selected artworks, together with newly added artworks from the Shanghai art world, were displayed in Shanghai. The participating artists included Wu Hufan, Feng Chaoran 馮超然 (1882-1954) and Chen Ziqing 陳子清 (1895-1946). ${ }^{63}$ Ma Gongyu was a renowned calligrapher while Feng Chaoran was a sought-after artist in the art market in pre-war Shanghai. The participation of these renowned artists in these artistic activities in a way suggests that the SJCA received support from the Shanghai art world.

Between 1942 and 1945, the SJCA worked closely with the Shanghai art world and Japanese art associations. It was thus able to bring Japanese art and artists

59 'Guofu huandu jinian zhong heping jianguo wenxian zhanlanhui xunli' (Exhibition of Writings on Peace and Building the Nation to Commemorate the Return of the National Government), Qingnian liangyou (The Young Companion) 2, 3 (1941): 25.

6o 'Sino-Japanese Cultural Association documents', Shanghai Municipal Archives, R1-16-1072.

61 'Yishu jie dongtai: Shanghai yanghua xuehui dingqi chengli' (Updates on the art world: a date has been set for the founding of the Shanghai Association for Western Painting), Shanghai yishu yuekan (Art in Shanghai Monthly) 7/8 (1942): 140.

62 Liu Yansheng, 'Si ji Xingya shudao zhan zhuanye: shudao zhanlanhui guanping' (Special Issue on the Fourth Exhibition of Reviving Asian Calligraphy: some comments on the Calligraphy Exhibition), Shishi huabao (Current Affairs Pictorial) 84 (1942): 11.

63 Shanghai Municipal Archives, R1-16-1072. 
to Shanghai. This is evident from the increasing number of exhibitions of Japanese art held in Shanghai. For example, by early 1943, the sJCA had organised eleven exhibitions of what it referred to as 'Chinese painting' (Zhongguo hua) and 'Japanese painting' (Riben hua), eight exhibitions of calligraphy, seven exhibitions of yanghua and three of woodblock prints (mubanhua). In addition, talks about nanga (lit., 'southern-style painting'; the Japanese adaptation of Chinese literati painting) and Japanese woodblock prints were held. More than half of these exhibitions involved Japanese artists. ${ }^{64}$

Interestingly, the SJCA was thus instrumental in introducing new terms and a new hierarchy into the discourse of art in occupied Shanghai. For example, the SJCA now classified painting into four main categories: 'Chinese painting' (Zhongguo hua), 'Japanese painting' (Riben hua), 'Manchurian painting' (Manzhou hua) and 'Western painting' (Xiyang hua). The former three categories were grouped under the terms of 'nanga' or 'shuhua' (painting-andcalligraphy), which was repackaged as a continuation of Chinese literati tradition. Although the term Zhongguo hua was used interchangeably with guohua, the emergence of the former indicated that a new classificatory logic had been invented by the SJCA to categorise artistic styles according to the new political order created under occupation.

To celebrate the Republic of China's National Day in October 1942, the SJCA invited artists in Shanghai to select exhibits for the First National Art Exhibition in Nanjing. Three artists were appointed to serve as jury members: Qian Shoutie, who specialised in seal carving; ${ }^{65}$ Xiong Songquan 熊松泉 (1884-1961), for painting and calligraphy; and Chen Baoyi, an expert on Western painting. Qian and Chen had been trained in Japan, so they were able to communicate with Japanese committee members. Xiong was a committee member of the Painting Association of China. The association selected and collected 105 works from Chinese and Japanese artists in Shanghai. Twelve oil paintings by Chinese artists were exhibited, such as old paintings by Yan Wenliang and Zhang Chongren, as well as new works by the women artists Guan Zilan 關紫蘭 (1903-1986) and Tang Yunyu 唐䔋玉 (1906-1992). According to a review article published in Pacific Ocean Weekly, the oil paintings were of poor quality, but most of

64 'Zhong-Ri wenxie Hu fenhui liang nian lai gongzuo zhuangkuang' (The work of the Shanghai branch of the Sino-Japanese Cultural Association over the past two years), Shenbao, 23 February 1943: 4.

65 On the friendship between Qian and Japanese art circles, particularly Hashimoto Kansetsu, see Aida Wong, 'A Chinese seal carver in Japan: Qian Shoutie and the literati world of Hashimoto Kansetsu', in Turmoil, Representation, and Trends: Modern Chinese Painting, 1796-1949, eds James Spencer and Qingli Wan (Kaohsiung: Kaohsiung Museum of Fine Arts, 2007), 425-45o. 
the guohua works in the exhibition were, in fact, of a high quality (though the works by Zhang Daqian and Wu Changshou included in the show were forgeries). ${ }^{66}$ Guohua works were also prominent in terms of number. Furthermore, the majority of the works by Chinese artists were guohua (thirty pieces), and most of the works by Japanese artists were yanghua (twenty-five pieces), indicating that another interesting relationship developed under full occupation. By that time, the term yanghua, a Chinese adaptation of the Japanese term yogga, had replaced the term xihua in the discourse on art, revealing the dominance of Japan. This is also evident from the proportions of guohua and Japanese yanghua, reflecting the new artistic order and the hierarchy embedded in the discourse of art in occupied China, in line with the concept of PanAsianism.

In a talk entitled 'Chinese and Japanese culture and the East Asian Renaissance', Zhou Huaren 周化人 (1903-1976) - chairman of the China branch of the East Asian League (Dong Ya lianmeng) - argued that ancient Asian culture originated in China, and that Japan was the most advanced culture in modern Asia. Almost all Asian cultures were influenced by China and inspired by modern Japanese culture, particularly since the successful Meiji Restoration. Therefore, Chinese and Japanese cultures were the crucial foundation that could bring about an 'East Asian Renaissance' (Dong Ya wenyi fuxing). ${ }^{67}$ Zhou also related the idea of Greater Asianism to Sun Yat-sen's 'Three Principles of the People', noting that:

President [Sun] has said that, in order to make Asianism a reality, the traditional culture of the East must be revived. This culture embodies the Kingly Way [wangdao], or ideals of benevolence and virtue [renyi daode] ... the culture of the Orient [Dongfang] has always been very strong. But in order to resist the material civilisation of western Europe, virtue and benevolence are not enough on their own. Thus the president encouraged the study of Western science, a point which he also stressed in his lectures on nationalism. ${ }^{68}$

\footnotetext{
66 Guangyi, 'Zuijin de Shanghai huatan', 706.

67 Zhou Huaren, 'Lunzhe: Zhong-Ri wenhua yu Dongya "wenyi fuxing”' (Review: Chinese and Japanese cultures and the East Asian Renaissance), Hansheng (Voice of the Han) 4 (1941): 4-10.

68 Torsten Weber, 'Nanjing's greater Asianism: Wang Jingwei and Zhou Huaren, 1940', in PanAsianism: A Documentary History 1860-2010, Vol. 2, eds Sven Saaler and C.W.A. Szpilman (Lanham, MD: Rowman \& Littlefield, 2011), 217.
} 
Sun Yat-sen's concepts of Greater Asianism and the East Asian Renaissance were instilled in the discourse of art, linked with the idea that 'Asia is one', as put forward by Okakura Kakuzō in his discussion of East Asian art. ${ }^{69}$

To accomplish this 'East Asian Renaissance', it was believed that the first and most important task was to revive Chinese culture. ${ }^{70}$ Chinese literati painting was framed as a root of Asian art (that had been inherited by the Japanese nanga), whereas Japanese oil painting and nihonga (Japanese painting) represented successful models of the modernisation of Asian art through the adoption of Western techniques. In the prevailing discourse of art, nanga was represented as an adaptation of Chinese literati painting or the 'Southern School', characterised by abbreviated brushwork, and thus distinct from the realistic style of the 'Northern School: ${ }^{71}$ In the late nineteenth and early twentieth centuries, Japan became a crucial centre for the study of Western painting for students from Asia, where first-hand materials such as European oil paintings and translated books could be accessed. The success of the Meiji Restoration was deemed the crucial juncture diverting the flow of cultural influence from Japan to China. ${ }^{72}$ Thus, in the discourse of Asian art in occupied China, it was believed that Chinese 'free-style' (xieyi) paintings should be introduced to Japan, and Western painting techniques should be brought to China from Japan. ${ }^{73}$ Unsurprisingly, therefore, the SJCA organised a considerable number of exhibitions on Japanese oil paintings, while supporting and extolling guohua.

In October 1943, the SJCA was restructured to orchestrate cultural activities, connect the Chinese and Japanese art worlds and eliminate toxic 'AngloAmerican' thought. By encouraging exchange between the Chinese and Japanese art worlds, the association sought to achieve the ultimate goal of creating a new East Asian culture. After this restructuring, Chen Gongbo was appointed as chairman of the SJCA, and Chu Minyi as one of its advisory members. Undoubtedly, by that time, most of the prestigious artists from the

69 Kokusai Bunka Shinkōkai (ed.) Xiandai Riben huihua zhanlanhui (Exhibition of Modern Japanese Paintings) (Tokyo: Kokusai Bunka Shinkōkai, 1943), 4.

70 Zhong-Ri wenhua xiehui (ed.), Zhong-Ri wenhua xiehui Dong Ya wenyi fuxing yundong tekan (Special Issue on the Greater East Asian Renaissance Movement) (Np: Zhong-Ri wenhua xiehui, 1942), 9 .

71 Tao Kangde, Riben guankui (A Peek into Japan) (Shanghai:Yuzhou feng she, 1936), 124-128.

72 Wang Xiangrong, 'Zhong-Ri wenhua diwei de nizhuan' (The reversal of position of Chinese and Japanese cultures), Zhong-Ri wenhua (Chinese and Japanese Cultures) 2, 8 (1942): 813 .

73 'Ri wenhua zhenxing hui zhucui Zhong-Ri shuhua zuotan jilu' (A record of Japan's International Culture Revival Association's meeting for the discussion on Chinese and Japanese painting and calligraphy), Shenbao, 21 June 1943: 4. 
Shanghai art world, particularly guohua artists, had served on the committee of the SJCA. For instance, Liu Haisu was an honorary committee member, having returned to Shanghai under an arrangement with the Japanese in May $1943 .{ }^{74}$ Similarly, Wu Hufan, Wu Zheng 吳徵 (1878-1949), Wang Yachen, Ma Gongyu, Song Songquan, Lang Jingshan 朗靜山 (1892-1995) and Chen Baoyi all served as committee members. ${ }^{75} \mathrm{Wu}$ Zheng was a renowned artist, and one of the most expensive, while Lang Jingshan was a leading photographer in the prewar Shanghai art world. In other words, the SJCA led to the creation of a new order in the art world of occupied Shanghai, with reputable artists all being eventually persuaded to join the association. ${ }^{76}$

In its 1943 October issue, Pacific Ocean Weekly published an article entitled 'Profiles of four literati artists in Shanghai,'77 highlighting Wu Hufan, Zheng Wuchang, Li Jian 李健 (1882-1956) and Wang Shengyuan 汪聲遠 (1889-1969). Wang taught at the Shanghai Art Academy between 1942 and 1952, and Li between 1935 and $1951 .{ }^{78}$ Liu Haisu was praised as the the lion of Oriental art' 東方藝術的獅子 by Hashimoto Kansetsu and as the 'great master of the Chinese cultural renaissance' 中國文藝復興大師 in the press. ${ }^{79}$ Works by Wu Hufan, Zheng Wuchang, Liu Haisu and Chen Baoyi were included in the Second National Art Exhibition..$^{80}$ Zheng and Wu organised joint exhibitions with their students in 1943 and 1944, respectively. ${ }^{81}$ Wu Hufan was invited by Zhu Pu 朱 樸 (1902-1970) to contribute articles and paintings to the magazine Gujin and

74 Liu Haisu, 'Nan you yinxiang' (Impressions of a journey to the south), Taipingyang zhoubao (Pacific Ocean Weekly) 1, 69 (1943): 1416.

75 'Zhong-Ri wenhua xiehui Shanghai fenhui zuo juxing gaizu chengli dianli' (The Shanghai branch of the Sino-Japanese Cultural Association held a ceremony for structural reorganisation yesterday), Shenbao, 5 October 1943: 3 .

76 Wang, Wang Yachen Rong Junli nianpu hebian, 286.

77 Wang Cheng, 'Hu di wenren hua si jia xiang' (Profiles of four literati artists in Shanghai), Taipingyang zhoubao (Pacific Ocean Weekly) 1, 84 (1943): 1851-1852.

78 Ma Haiping, Shanghai meizhuanmingren zhuanlüe (Brief Biography of Celebrities of Shanghai Training School of Fine Arts) (Nanjing: Nanjing University Press, 2012), 207, 129.

79 Wu'an zhuren, 'Ji Liu Haisu' (A note on Liu Haisu), Taipingyang zhoubao (Pacific Ocean Weekly) 1, 91 (1943): 2040; 'Zhongguo wenyi fuxing dashi: Liu Haisu yi xi tan' (The Great Master of the Chinese Cultural Renaissance Liu Haisu returned to Shanghai and gave a talk), Taipingyang zhoubao (Pacific Ocean Weekly) 1, 67 (1943): 1359.

8o 'Huiwu baogao: shiyi yue yi ri deng' (Report of the Association: 1 November and others), Wenxie (The Literary Association) 1, 2 (1943): 29-30.

81 'Zhang Wuchang shisheng shuhua yimai zhuxue shengkuang' (A report of the Charity Exhibition of Paintings and Calligraphy by Zheng Wuchang and his students for children's school fees), Shenbao, 12 May 1943: 4; 'Meijing shuwu tongmen juxing huazhan' (The students of the Plum Vista Studio organised a painting exhibition), Shenbao, 14 July 1944: 2. 


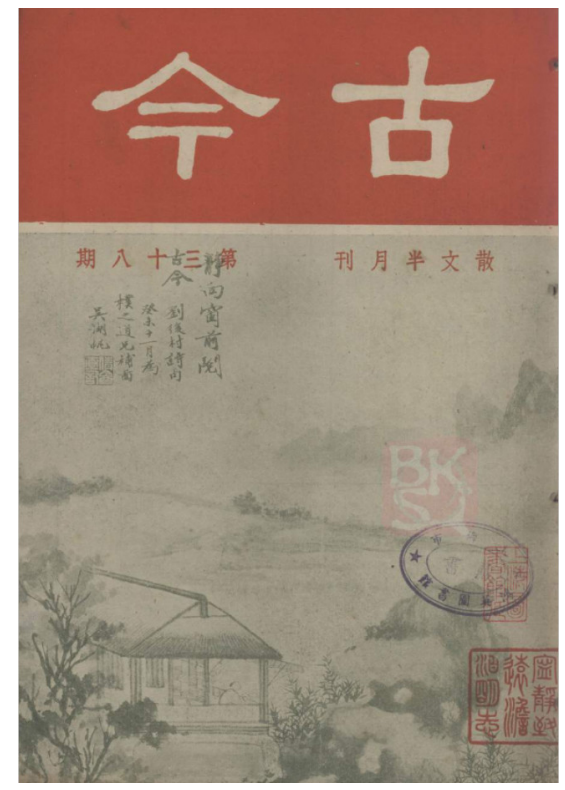

FIGURE 4

The cover of the magazine Gujin decorated with a painting specifically created by $\mathrm{Wu}$ Hufan for the magazine in 1944

praised by Zhu as 'the best master painter in Jiangnan' 江南第一畫師. ${ }^{82}$ (See Figure 4.) Wu published his painting catalogue in 1943, with this being praised as a revival of Chinese painting. ${ }^{83}$ His students were allowed to establish the Chinese Painting Garden to exhibit and sell guohua.

A solo exhibition of works by Liu Haisu was held at the Chinese Painting Garden in December 1943, featuring sixty-one guohua and fifty-nine xihua. The exhibition was widely reported and reviewed. A review of the exhibition stated that Liu excelled in both guohua and xihua, and was able to blend the two to give birth to his own personal style. The article highlighted Liu's contribution to the art world, stating that Liu was the founder of the Shanghai Academy of Arts and had travelled to Europe several times to bring Chinese art to European national museums. Recently, Liu had travelled to Southeast Asia and returned to Shanghai, so he organised the exhibition to share his latest paintings with his admirers. ${ }^{84}$ Chen Binhe 陳彬滄 (1897-1945), the chief editor of Shenbao, even

$82 \mathrm{Zhu} \mathrm{Pu}$, the publisher of the magazine Gujin, was a supporter of the Peace Movement and involved in Wang Jingwei's cultural projects. Fu, Passivity, Resistance, and Collaboration, 127; Zhu Pu, 'Gujin liang nian' (Two years since the publication of Gujin), Gujin 43/44 (1944): 47 .

83 Wu Hufan, Meiying huaji (Paintings by Wu Hufan) (Shanghai: Meiying shuwu, 1943).

84 'Liu Haisu shi huazhan jia Zhongguo huayuan juxing' (Liu Haisu will hold a painting exhibition at the Chinese Painting Garden), Shenbao, 28 November 1943: 3. 
penned a preface to the exhibition catalogue. ${ }^{85}$ The exhibition was visited by politicians, artists and businessmen. ${ }^{86}$

\section{$5 \quad$ Conclusion}

After the end of the war, some of the core members of the sJCA were arrested and imprisoned. Liu Haisu's name was included on a list of cultural traitors published in the New China Daily (Xinhua ribao), along with Chen Binhe, who was accused of accepting an invitation from the Japanese to return to Shanghai and promote the idea of 'greater Japan'. ${ }^{87}$ Liu Haisu was accused of supporting the occupiers and the 'collaborationists' by accepting an offer to return to Shanghai to 'construct and revive the Greater East Asia Culture Renaissance', to serve as an honorary member of the committee of the SJCA, and to lead the art world in occupied China. ${ }^{88} \mathrm{Wu}$ Hufan was named as a 'collaborator' because of his connections with the Gujin Group and Wang Jingwei's regime. He was even rumoured to have dedicated a painting entitled Return to the Capital (Huandu) to Wang's regime. ${ }^{89}$ Although the rumour about this painting was later discredited, Wu was held in a hotel for months before his eventual release. ${ }^{90}$ In contrast, though Zheng Wuchang also engaged with artistic activities organised by Wang's regime, he was praised for maintaining his moral integrity during the war. ${ }^{91}$ Perhaps this is because Zheng was not listed as a committee member of the SJCA. However, other committee members such as Wang Yachen were not named as 'collaborationists'.

85 Chen Binhe, 'Liu Haisu xiansheng huazhan yinyan' (An introduction to Liu Haisu's exhibition of paintings), Shenbao, 29 November 1943: 4.

86 'Liu Haisu huazhan zuo yuzhan shengkuang' (The success of the preview of Liu Haisu's exhibition of paintings yesterday), Shenbao, 3 o November 1943: 3 .

87 'Wenhua Hanjian minglu' (A list of cultural traitors), Xinhua ribao (New China Daily), 23 August 1945 .

88 'Liu Haisu yi shi wucheng' (Liu Haisu accomplished nothing), Hanjian chou shi (Hideous Histories of Chinese Traitors) 5 (1945): 11-13.

89 Tiange, Qun chou xianxing ji (An Exposure of an Ugly Bunch) (Shanghai: Zhengxing chubanshe, 1945), 47-49.

$90 \quad$ Li Shibai, 'Wu Hufan huandu zhi mi' (The mystery of Wu Hufan's "Return to the Capital"), Dongnanfeng (Southeast Wind) 13(1946):12; Dai Xiaojing, Wu Hufan:Xiandai shanshuihua dashi (Wu Hufan: A Master of Modern Landscape Painting) (Shanghai: Shanghai jiaoyu chubanshe, 2000).

91 Zhizhi Laoren, 'Zheng Wuchang zuo ji ming' (Zheng Wuchang is crowing like a rooster), Kuaihuo lin (The Merry Voice) 1 (1946): 2. 
In wartime Shanghai, guohua works were regarded as a commodity-an investment, a symbol of Chinese elite culture and the root of East Asian art, endorsed by Wang's regime and by the occupying Japanese. Wang Jingwei and his subordinates declared their preference for this traditional Chinese art form, both as a demonstration of the regime's legitimacy as the political and cultural leader of 'new China', and as a continuation of the cultural policies of the pre-war Republican government, which had promoted guohua as China's representative art form. In the discourse of the new order of East Asian art, guohua was deemed one of the crucial pillars of the East Asian Renaissance, with a status equal to that of Japanese modern art. Thus, guohua continued to dominate the art world, and prominent guohua artists such as Wu Hufan, Zheng Wuchang and Liu Haisu were all celebrated during the post-gudao, full occupation period.

In 1947, a yearbook on the Chinese art world was published. However, mention of the SJCA and the Shanghai Tairiku Gallery was absent from this publication, as were terms such as 'East Asian art/culture'. Even more interestingly, this book included a series of artist biographies that included most of the artists who had been active in occupied Shanghai. Although Wu Hufan, Liu Haisu and Wang Yachen had served as committee members for the SJCA, their names were included in the yearbook as a way to show that they had been re-accepted by the post-war art world. Perhaps it was the case that their actions during the occupation had been judged not to have damaged the nation, and their involvement with the SJCA could be justified as an effort to preserve traditional Chinese culture at a time of national crisis. Intriguingly, the accounts of $\mathrm{Wu}$ Hufan, Liu Haisu, Zheng Wuchang, Wang Yachen, Li Qiujun and Chen Xiaocui that were published in this yearbook were all sanitised, eschewing any mention of their activities during the war. According to one account, for example, Xu Banda (one of Wu Hufan's students),

together with Chen Dingshan, Li Zuhan and Wang Jiqiang, founded the Chinese Painting Garden to facilitate exhibitions and benefit the members of the art world. During the War of Resistance, he was trapped in Shanghai and never contacted the outside world.

\section{與陳定山李祖韓王季遷等, 創立中國畫苑, 以便美術展覽, 人稱便 之。抗戰時, 困守上海不與外接。92}


Of course, this was another kind of distortion of history: Xu's name did appear in newspapers during the occupation. Indeed, almost all of the artists mentioned in this paper had been engaged or involved in artistic activities either related to or supported by the Wang Jingwei regime or the occupying Japanese in one way or another. The extent of their involvement and their connections with the officials of the Wang Jingwei regime mattered in terms of moral judgements after the war. However, layered meanings attached to guohua complicate the question of what counts as collaboration or resistance in the realm of art in the context of the Sino-Japanese War. Engagement with artistic activities could be justified as promoting Chinese cultural tradition on the one hand or the 'Asia is one' ideology on the other. There is little information to show how guohua artists actively resisted the Wang Jingwei regime. However, interestingly, the twisted narrative of artists' resistance in occupied Shanghai can be found in sanitised artists' biographies published in the late twentieth century. In Liu Haisu's chronology, the accounts of 1939 and 1943 state that Liu organised exhibitions in Southeast Asia to raise funds to aid the War of Resistance, and that after returning to Shanghai he refused to take part in any activities organised by the Wang Jingwei regime. ${ }^{93}$ In fact, artistic activities during the occupation are still the missing piece of the puzzle in the grand narrative of modern Chinese art history. For instance, Lü Peng has excluded occupied areas in his narrative of the art history of wartime China in his newly published book A History of Modern Art in China. ${ }^{94}$

\section{Acknowledgments}

Research for this paper was supported by the Research Grants Councils of the Hong Kong SAR, China (Project no. 14601819). An earlier version was first presented at the workshop 'Cultural and Intellectual Histories of Japaneseoccupied China', held at Asia House (London) on 16 September 2019. This workshop was organised through the сотсA Project, and was thus supported by the European Research Council (ERC) under the European Union's Horizon 2020 research and innovation programme (Grant no. 682081). I thank the organisers and participants of the workshop (especially Jeremy E. Taylor) and the anonymous reviewers for their comments and suggestions. I am also indebted to Siyi $\mathrm{Li}$, Yan Liang and Caddie Lau for their assistance and support.

93 Xu Jianrong, Liu Haisu (Suzhou: Guwu Xuan chubanshe, 1999), 129.

94 Lü Peng, Zhongguo xiandai yishu shi (A History of Modern Art in China) (Shanghai: Shanghai shuhua chubanshe, 2019). 


\section{References}

Andrews, Julia F., and Kuiyi Shen. 'Traditionalism as a modern stance: the Chinese Women's Calligraphy and Painting Society of 1930s Shanghai'. Modern Chinese Literature and Culture 11, 1 (Spring 1999):1-29.

Bertrand Dorléac, Laurence. Art of the Defeat: France 1940-1944. Translated by Jane Marie Todd (Los Angeles: Getty Research Institute, 2008).

Brook, Timothy. Collaboration:Japanese Agents and Local Elites in Wartime China (Cambridge, MA: Harvard University Press, 2005).

Chan, Pedith Piu. The Making of a Modern Art World: Institutionalisation and Legitimisation of Guohua in Republican Shanghai (Leiden: Brill, 2017).

Chen Binhe. 'Liu Haisu xiansheng huazhan yinyan' (An introduction to Liu Haisu's exhibition of paintings). Shenbao, 29 November 1943: 4.

Chen Dingshan. 'Zhongguo huayuan zheng hua ji' (Chinese Painting Garden's call for paintings). Shenbao, 29 August 1943: 3 .

Chen Dingshan. Chunshen jiuwen (Old Stories of Shanghai) (Taipei: Duli zuojia, 2016). Chou Fangmei. 'Zhongguo xihuajia de "Dongfang zhuyi"?-Di'erci shijie dazhan shi Zhongguo shaoshu minzu de xingxiang' (The Chinese frontier-images of minorities during WWII). Yishuxue yanjiu (NCU Journal of Art Studies) 1 (June 20o6): 59101.

Chu Minyi. Zhong-Ri wenhua xiehui kaimu dianli tekan (Special Issue on the Opening of the Sino-Japanese Cultural Association) (Np: Zhong-Ri wenhua xiehui, 1940).

Cone, Michèle. Artists under Vichy: A Case of Prejudice and Persecution (Princeton, NJ: Princeton University Press, 1992).

Dai Xiaojing. Wu Hufan: Xiandai shanshuihua dashi (Wu Hufan: A Master of Modern Landscape Painting) (Shanghai: Shanghai jiaoyu chubanshe, 2000).

Duara, Prasenjit. 'The discourse of civilization and Pan-Asianism', Journal of World History 12,1 (Spring, 2001): 99-130.

FitzGerald, Carolyn. Fragmenting Modernisms: Chinese Wartime Literature, Art and Film, 1937-1949 (Leiden: Brill, 2013).

Fu, Poshek. Passivity, Resistance, and Collaboration: Intellectual Choices in Occupied Shanghai, 1937-1945 (Stanford, CA: Stanford University Press, 1993).

'Ge shangtuan lingxiu jiyi Wang Yiting sishi' (Leaders of corporations discussed the posthumous name of Wang Yiting). Shenbao, 10 December 1938: 1.

Guangyi. 'Zuijin de Shanghai huatan' (The recent Shanghai art world). Taipingyang zhoubao (Pacific Ocean Weekly) 1, 40 (1942): 706.

'Guofu huandu jinian zhong heping jianguo wenxian zhanlanhui xunli' (Exhibition of Writings on Peace and Building the Nation to commemorate the return of the National government). Qingnian liangyou (The Young Companion) 2, 3 (1941): 25 . 
'He Tianjian shuhua xun' (Painting-and-calligraphy news of He Tianjian). Shenbao, 14 November 1940: 11.

Huang, Nicole. Women, War, and Domesticity: Shanghai Literature and Popular Culture of the 1940s (Boston: Brill, 2005).

Huang Yuanlin (ed.). Bainian manhua (A Hundred Years of Cartooning), vols 1, 2 (Beijing: Xiandai chubanshe, 2000).

'Huiwu baogao: shiyi yue yi ri deng' (Report of the Association: 1 November and others). Wenxie (The Literary Association) 1, 2 (1943): 29-30.

Hung, Chang-tai. War and Popular Culture: Resistance in Modern China, 1937-1945 (Berkeley: University of California Press, 1994).

Hung, Chang-tai. 'Two images of socialism: woodcuts in Chinese Communist politics'. Comparative Studies in Society and History 39, 1 (January 1997): 34-6o.

Ji Zhusheng. 'Guohua ji Shanghai de guohua jia' (National painting and national-style painters in Shanghai). Taipingyang zhoubao (Pacific Ocean Weekly) 1, 21 (1942): 248249.

'Jian xun' (Brief news). Shenbao, 2 July 1944: 3 .

'Jian xun' (Brief news). Shenbao, 26 November 1944: 2.

'Jieyue yundonghui juxing xuanchuan zhou' ([Organisers of] the Savings Campaign hold the promotion week). Shenbao, 8 November 1943: 2.

Kokusai Bunka Shinkōkai (ed.). Xiandai Riben huihua zhanlanhui (Exhibition of Modern Japanese Paintings) (Tokyo: Kokusai Bunka Shinkōkai, 1943).

Li Shibai. 'Wu Hufan huandu zhi mi' (The mystery of Wu Hufan's "Return to the Capital"). Dongnan feng (Southeast Wind) 13 (1946): 12.

Liu Haisu. 'Nan you yinxiang' (Impressions of a journey to the south). Taipingyang zhoubao (Pacific Ocean Weekly) 1, 69 (1943): 1416.

'Liu Haisu huazhan zuo yuzhan shengkuang' (The success of the preview of Liu Haisu's exhibition of paintings yesterday). Shenbao, 3 o November 1943: 3.

'Liu Haisu shi huazhan jia Zhongguo huayuan juxing' (Liu Haisu will hold a painting exhibition at the Chinese Painting Garden). Shenbao, 28 November 1943: 3.

'Liu Haisu yi shi wucheng' (Liu Haisu accomplished nothing). Hanjian chou shi (Hideous Histories of Chinese Traitors) 5 (1945): 11-13.

Liu Yansheng. 'Si ji Xingyu shudao zhan zhuanye: shudao zhanlanhui guanping' (Special issue on the Fourth Exhibition of Reviving Asian Calligraphy: some comments on the calligraphy exhibition). Shishi huabao (Current Affairs Pictorial) 84 (1942): 11.

Lü Peng. Zhongguo xiandai yishu shi (A History of Modern Art in China) (Shanghai: Shanghai shuhua chubanshe, 2019).

Ma Haiping. Shanghai meizhuan mingren zhuanlüe (Brief Biography of Celebrities of Shanghai Academy of Art) (Nanjing: Nanjing daxue chubanshe, 2012).

'Meijing shuwu tongmen juxing huazhan' (The students of the Plum Vista Studio organised a painting exhibition). Shenbao, 14 July 1944: 2. 
'Nianlai jixing fada' (Unusually robust development [of art] in the past years). Shenbao, 9 March 1942: 3 .

'Nüzi shuhua zhan di'er tian shengkuang' (The success of the Exhibition of Calligraphy and Paintings by Female Artists on the second day). Shenbao, 28 November 1938: 11.

'Nüzi shuhua zhan kaimu' (Exhibition of Calligraphy and Paintings by Female Artists opens). Shenbao, 8 November 1941: 8.

'Nüzi shuhuahui zuo kaimu' (Exhibition of works by the Chinese Women's Painting and Calligraphy Association opened yesterday). Shenbao, 9 November 1941:10.

'Nüzi shuhuahui jin kaimu' (Exhibition of works by the Chinese Women's Painting and Calligraphy Association opens today). Shenbao, 11 November 1939: 12.

'Nüzi shuhuahui wu jie zuopin zhanlan' (The Fifth Exhibition of Works by the Chinese Women's Painting and Calligraphy Association). Shenbao, 26 November 1938: 12.

'Ri wenhua zhenxing hui zhucui Zhong-Ri shuhua zuotan jilu' (A record of Japan's International Culture Revival Association's meeting for the discussion on Chinese and Japanese painting and calligraphy). Shenbao, 21 June 1943: 4.

Riding, Alan. And the Show Went On: Cultural Life in Nazi-occupied Paris (New York: Alfred A. Knopf, 2010).

Saaler, Sven. 'The Kokuryūkai (Black Dragon Society) and the rise of nationalism, PanAsianism, and militarism in Japan, 1901-1925'. International Journal of Asian Studies 11, 2 (2014): 125-16o.

Saaler, Sven, and Victor Koschmann (eds). Pan-Asianism in Modern Japanese History: Colonialism, Regionalism and Borders (Abingdon: Routledge, 2007).

Saaler, Sven, and Christopher W.A. Szpilman (eds). Pan-Asianism: A Documentary History (Lanham, MD: Rowman \& Littlefield, 2011).

Shenbao nianjian (minguo sanshisan nian du) (Shenbao Yearbook, 1944) (Shanghai: Shenbao nianjian she, 1944).

'Sino-Japanese Cultural Association documents'. Shanghai Municipal Archives, R1-161072.

Spotts, Frederic. The Shameful Peace: How French Artists and Intellectuals Survived the Nazi Occupation (New Haven, CT: Yale University Press, 2008).

Tiange. Qun chou xianxing ji (An Exposure of an Ugly Bunch) (Shanghai: Zhengxing chubanshe, 1945).

Tankha, Brij. Okakura Tenshin and Pan-Asianism: Shadows of the Past (Leiden: Brill, 2008).

Tao Kangde. Riben guankui (A Peek into Japan) (Shanghai: Yuzhou feng she, 1936).

Taylor, Jeremy E. 'Cartoons and collaboration in wartime China: the mobilization of Chinese cartoonists under Japanese occupation'. Modern China 41, 4 (July 2015): 406-435.

Wang Cheng. 'Hu di wenren hua si jia xiang' (Profiles of four literati artists in Shanghai). Taipingyang zhoubao (Pacific Ocean Weekly) 1, 84 (1943): 1851-1852. 
Wang Cheng. 'Xin qiu san huazhan' (Three exhibitions of paintings in early autumn). Taipingyang zhoubao (Pacific Ocean Weekly) 1, 81 (1943): 1764.

Wang Yichang (ed.). Zhongguo meishu nianjian, 1947 (1947 Yearbook of Chinese Art), History 9 (Shanghai: Shanghai shi wenhua yundong weiyuanhui, 1948).

Wang Yuren. 'Liu Haisu yinxiang' (Impressions of Liu Haisu). Taipingyang zhoubao (Pacific Ocean Weekly) 1, 22 (1942): 275.

Wang Xiangrong. 'Zhong-Ri wenhua diwei de nizhuan' (The reversal of position of Chinese and Japanese cultures). Zhong-Ri wenhua (Chinese and Japanese Cultures) 2, 8 (1942): 8-13.

Wang Zhen. Wang Yachen Rong Junli nianpu hebian (Chronology of the Life of Wang Yachen and Rong Junli) (Beijing: Minchu yu jianshe chubanshe, 1996).

Weber, Torsten. 'Nanjing's greater Asianism: Wang Jingwei and Zhou Huaren, 1940'. In Pan-Asianism: A Documentary History 1860-2010, Vol. 2, edited by Sven Saaler and C.W.A. Szpilman (Lanham, MD: Rowman \& Littlefield, 2011).

'Weilao huazhan jiesu' (Closing of the painting exhibition for the consolation of soldiers). Shenbao, 12 November 1937: 9 .

'Weilao jiangshi shuhua zhan zuo bimu' (Calligraphy and painting exhibition for the consolation of soldiers closed yesterday). Shenbao, 6 November 1937: 6.

'Wenhua Hanjian minglu' (A list of cultural traitors). Xinhua ribao (New China Daily), 23 August 1945 .

Wong, Aida. 'A Chinese seal carver in Japan: Qian Shoutie and the literati world of Hashimoto Kansetsu'. In Turmoil, Representation, and Trends: Modern Chinese Painting, 1796-1949, edited by James Spencer and Qingli Wan (Kaohsiung: Kaohsiung Museum of Fine Arts, 2007), 425-450.

Woxin. 'Zhongguo huayuan xingjiang jieshu' (Chinese Painting Garden will close soon). Daguanyuan zhoubao (Panorama Garden Weekly) 4 (March 1946): 4.

Wu Hufan. Meiying huaji (Paintings by Wu Hufan) (Shanghai: Meiying shuwu, 1943).

'Xin yaji qiu xing huazhan' (New elegant gathering of the painting exhibition in autumn). Shenbao, 28 October 1941: 8.

Xu Jianrong. Liu Haisu (Suzhou: Guwu xuan chubanshe, 1999).

Xu Wancheng. Quanguo wenhuajiguan diaocha (An investigation into national cultural institutions) (Shanghai: Longwen shudian, 1943).

Yao Fei. 'A study of daily life in Shanghai during the isolated island period'. Chinese Studies in History 47, 3 (2014): 29-52.

Yin'an. 'Lidai shuhua zhan canguan ji' (Notes on a visit to an exhibition of paintings and calligraphy). Rensheng (Life) 1, 3 (1943): 16.

'Yishu jie dongtai: Shanghai yanghua xuehui dingqi chengli' (Updates on the art world: a date has been set for the founding of the Shanghai Association for Western Painting). Shanghaiyishuyuekan (Art in Shanghai Monthly) 7/8 (1942): 140. 
Zhang Jie. 'Yishu zabi' (Miscellaneous writing on art). Taipingyang zhoubao (Pacific Ocean Weekly) 1, 20 (1942): 226-227.

'Zhang Wuchang shisheng shuhua yimai zhuxue shengkuang' (A report of the Charity Exhibition of Paintings and Calligraphy by Zheng Wuchang and his students for children's school fees). Shenbao, 12 May 1943: 4.

Zhizhi Laoren. 'Zheng Wuchang zuoji ming' (Zheng Wuchang is crowing like a rooster). Kuaihuo lin (The Merry Voice) 1 (1946): 2.

'Zhongguo wenyi fuxing dashi: Liu Haisu yi xi tan' (The Great Master of the Chinese Cultural Renaissance Liu Haisu returned to Shanghai and gave a talk). Taipingyang zhoubao (Pacific Ocean Weekly) 1, 67 (1943): 1359.

Zhong-Ri wenhua xiehui (ed.). Zhong-Ri wenhua xiehui zhounian jinian tekan (Special Issue Commemorating the First Anniversary of the Sino-Japanese Cultural Association) (Np: Zhong-Ri wenhua xiehui, 1941).

Zhong-Ri wenhua xiehui (ed.). Zhong-Ri wenhua xiehui Dong Ya wenyi fuxing yundong tekan (Special Issue on the Greater East Asian Renaissance Movement) (Np: ZhongRi wenhua xiehui, 1942).

Zhong-Ri wenhua xiehui (ed.). Zhong-Ri wenhua xiehui er zhounian jinian tekan (Special Issue on the Second Anniversary of the Sino-Japanese Cultural Association) (Np: Zhong-Ri wenhua xiehui, 1942).

Zhong-Ri wenhua xiehui (ed.). Zhong-Ri wenhua xiehui Shanghai fenhui gongzuo baogao (Report on the Work of the Shanghai Branch of the Sino-Japanese Cultural Association) (Np: Zhong-Ri wenhua xiehui, 1942).

'Zhong-Ri wenhua xiehui Shanghai fenhui zuo juxing gaizu chengli dianli' (The Shanghai branch of the Sino-Japanese Cultural Association held a ceremony for structural reorganisation yesterday). Shenbao, 5 October 1943: 3 .

'Zhong-Ri wenhua xiehui yuanqi' (The origins of the Sino-Japanese Cultural Association). Waijiaobu gongbao (Bulletin of the Ministry of Foreign Affairs) 7 (1940): 1920.

'Zhong-Ri wenxie Hu fenhui liang nian lai gongzuo zhuangkuang' (The work of the Shanghai branch of the Sino-Japanese Cultural Association over the past two years). Shenbao, 23 February 1943: 4.

'Zhongguo huayuan kaimu yugao' (Advance notice about the opening of the Chinese Painting Garden). Shenbao, 20 August 1943: 1.

Zhou Huaren. 'Lunzhe: Zhong-Ri wenhua yu Dongya “wenyi fuxing”' (Review: Chinese and Japanese cultures and East Asian Renaissance). Hansheng (Voice of the Han) 4 (1941): 4-10.

Zhu Pu. 'Gujin liang nian' (Two years since the publication of Gujin). Gujin 43/44 (1944): 47 .

Zhu Weiqi. 'Yi nian lai Shanghai meishu jie qingsuan' (An annual review of the Shanghai art world). Taipingyang zhoubao (Pacific Ocean Weekly) 1, 49 (1942): 929-931. 
Zhu Weiqi. 'Chuchun Shanghai huatan' (The Shanghai art world in early spring). Taipingyang zhoubao (Pacific Ocean Weekly) 1, 63 (1943): 1278.

Zhu Weiqi. 'San'er nian Shanghai meishu jie zongjian' (A review of the Shanghai art world in 1943). Taipingyang zhoubao (Pacific Ocean Weekly) 1, 93 (1944): 2096-2097. 